\title{
Experimental Study of Silty Clay Plane Strain Tri-axial Test under RTC Path and Modified Cam-clay Model
}

\author{
Tao Cheng ${ }^{a^{*}}$, Yi Zhang ${ }^{b}$, Keqin Yan ${ }^{a}$ \\ ${ }^{a}$ School of Civil Engineering, Huangshi Institute of Technology, Huangshi Hubei ,China. \\ ${ }^{b}$ Geodetic Institute, Leibniz Universität Hannover, Germany. \\ Received 20 January 2018; Accepted 28 February 2018
}

\begin{abstract}
The character of geomaterials is affected by stress path remarkably. Under different stress paths, the stressstrain characteristics of geomaterials are difference. For the unloading path in existing engineering situation, the physical parameters and constitutive model is usually determined by loading test. The path to uninstall the actual project conditions which may be a larger error. Therefore, this work proceeding from the actual project, deep excavation of the lateral unloading condition is analysed. The tests of CTC path and RTC path on silty clay in Huangshi city of china by multi-path tri-axial plane strain are carried on in the geotechnical Engineering Laboratory of Huangshi Institute of Technology. Then, the phenomenon under the two stress paths are compared with each other and describing the differences between them. The mechanical properties in the RTC stress path is analyzed mainly. Based on the Cam-Clay model framework, then derived this material yield equation based on Cam-clay model, Laiding the foundation for the numerical analysis.
\end{abstract}

Keywords: Silty Clay; RTC Stress Path; Plane Strain Test; Modified Cam-Clay Model.

\section{Introduction}

Soil is a complex material, its properties depends not only on the nature of the current stress state, but also the soil type, stress history and follow-up on the loading direction. Lamber [1,2] put forward the stress path method of soil, which provide a reasonable method for the study on strength and deformation characteristics of soil under different loading conditions. In recent years, since the concept of stress path has been proposed, researchers have begun to consider the influence of stress path in soil analysis. In recent years, Qin et al. [3] use large-scale tri-axial testing machine, the silk mica schist coarse aggregate for consolidation under constant confining pressure, drainage and consolidation undrained tri-axial test and consolidation test under conventional loading stress path (Increasing P stress path). Zhao et al. [4] use GCTS hollow cylindrical torsional shear apparatus such as the first marine sedimentary soft soil in Binhai new area of Tianjin was carried out under unloading stress path tri-axial test, such as increasing $\mathrm{P}$, reducing $\mathrm{P}$ stress path soils samples of stress and strain, pore water pressure and effective stress path, strain rate and other characteristics. Li [5] use GDS tri-axial apparatus to five types of stress path tri-axial tests were conducted on $\mathrm{K}_{0^{-}}$ consolidated Wenzhou saturated soft clay under undrained conditions, analysis of different stress - strain relationship of soil mass under the stress path, the path of development of pore pressure and effective stress. These research results show that stress path has a significant influence on the stress and strain relationship of geotechnical materials [19-23].

The change of stress field of soil in the pit caused by unloading pit excavation depends on the location, different

*Corresponding author: chtao_hust@163.com

http://dx.doi.org/10.28991/cej-0309112

$>$ This is an open access article under the CC-BY license (https://creativecommons.org/licenses/by/4.0/).

(C) Authors retain all copyrights. 
location withstand the stress paths of soil are not the same [6, 7]. In order to study deformation and strength characteristics of the soil under different stress paths, some scholars [8-10] have conducted site monitoring and stress path tri-axial tests. Based on the multi-path effect, Cheng [11-13] has studied deformation characteristics of clay under coupling multi-field. The results show characteristics of the soil exist significant difference under different stress paths. The strength characteristics, deformation law and failure mode of rock and soil material under unloading condition are significantly different from that of loading state. When conventional tri-axial compression test results of the analysis used for the Foundation, the results with the actual situation will often lead to considerable error.

With the Problems of numerical analysis of soil excavation, simulation for the unloading path is always achieved by controlling the Life and death of the cell. Feng and Jiang [14] have made are search about the constitutive models reflecting stress-strain relationship in lateral unloading condition, and the experimental results are simulated by conventional constitutive model, and the results are compared with the experimental results. Zhang et al [10] research results concluded that unloading stress path test results compared with the conventional tri-axial loading test have significant differences, the development can describe unloading stress path of soil constitutive model is necessary, the soil mass in accord with the Engineering practice of excavation of the deformation and stress analysis are necessary. There is yet a well by a quantitative analysis of the constitutive model for unloading path. Some extent, this method can be more desirable for numerical analysis under unloading problem. However, there may be some discrepancy for the actual working conditions. Therefore, this work is based on the constitutive model framework Cambridge, the model was modified by testing, obtained the modified Cambridge model based on this material.

\section{Loading and Unloading Plane Strain Test}

\subsection{Determination of Basic Physical Properties of Indicators}

Soil used in the experiment is from deep foundation construction site of Qing Long Mountain in Huangshi city of China. Because the samples have been dug by the different degrees of disturbance, and the characteristics analysis is taking into account mainly. Take remolded soil as the test samples. Remolding procedures are provided on the soil sample before tri-axial tests [15]. The testing of basic properties of the soil and preparation of remolded soil is on the basis of soil test procedures. Indicators of soil physical properties are shown in Table 1.

Table 1. Physical indicators of soil samples

\begin{tabular}{cccccc}
\hline $\begin{array}{c}\text { Saturated water } \\
\text { content }(\boldsymbol{\%})\end{array}$ & $\begin{array}{c}\text { Air-dry moisture } \\
\text { content }(\boldsymbol{\%})\end{array}$ & $\begin{array}{c}\text { Wet density } \boldsymbol{\rho} \\
(\mathbf{g} / \mathbf{c m})\end{array}$ & $\begin{array}{c}\text { Plasticity index } \boldsymbol{I}_{\boldsymbol{P}} \\
(\boldsymbol{\%})\end{array}$ & $\begin{array}{c}\text { Void } \\
\text { ratio } \boldsymbol{e}\end{array}$ & $\begin{array}{c}\text { Specific weight } \\
\boldsymbol{d}_{\boldsymbol{s}}\end{array}$ \\
\hline 23.6 & 2.0 & 2.03 & 15.3 & 0.517 & 2.7 \\
\hline
\end{tabular}

\subsection{Test Program}

Based on the plane strain, the test is conducted under the two stress path. The SY60C multi-path plane strain gauge conduct is used for the consolidation of multi-path plane strain test drainage. Loading and unloading process are repeated continuously during the test. To ensure the authenticity and reliability of data, automated data acquisition system is used for data acquisition. This work conducted tests under two paths. Test instruments and sample are shown in Figure.1.

1) CTC path base on plane strain: increase the average principal stress $P$ by the first, then remained confining pressure $\sigma_{3}$ as constant and increasing axial load $\sigma_{1}$ until the sample is damaged.

2) RTC path base on plane strain: increase the $P$ by the first, then remained axial load $\sigma_{1}$ as constant and reducing confining pressure $\sigma_{3}$ until the sample is damaged.
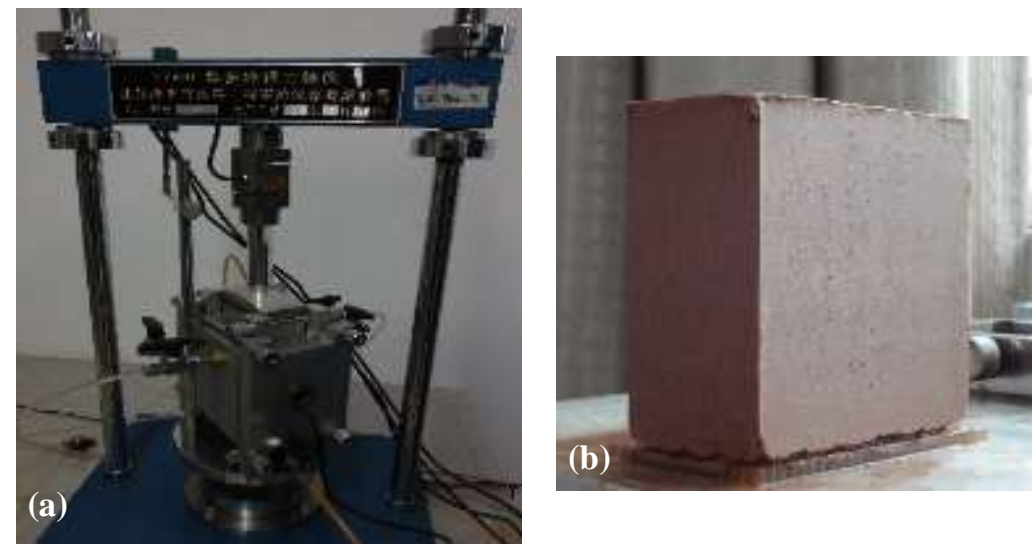

Figure 1. Test instruments and Test soil sample (a) Test instruments; (b) Test soil sample 
In order to compare the influence of different initial confining pressure on soil, the two stress path tests were conducted at different initial confining pressures, initial confining pressure is from 50-500 $\mathrm{kPa}$ equally spaced increments in accordance with $50 \mathrm{kPa}$. Loading rate and unloading rate is same as $0.017 \mathrm{~mm} / \mathrm{min}$. This stress components without the absence of special note are the effective stress. Expressed in the $p \sim q$ plane, the total test path is shown in Figure 2. In which, $q$ is the generalized shear stress.

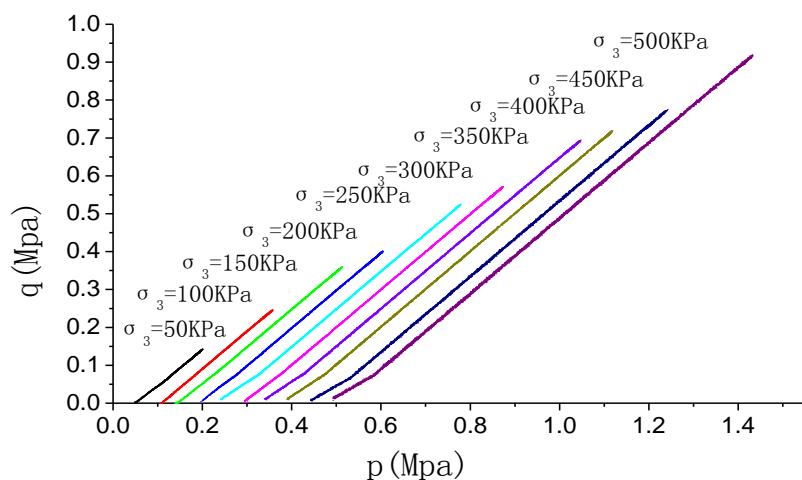

(a) CTC stress path

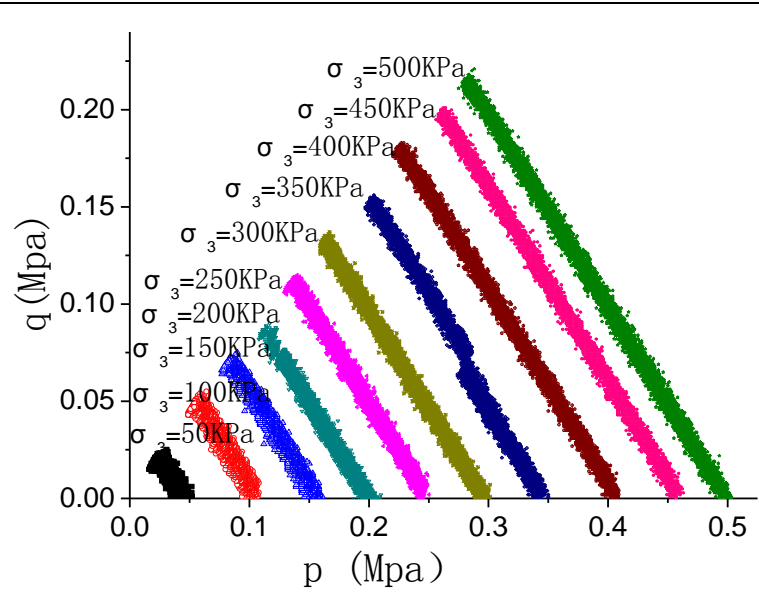

(b) RTC stress path

Figure 2. Test path of Clay samples

\subsection{Analysis of Experimental Phenomena}

Here are some stress-strain curves of silty clay under the two stress paths, Focus on the stress-strain behavior of clay with different loading paths and different stress history, as the fundamental basis for numerical modeling.

\section{1) Relation between principal stress difference $q$ and the axial strain $\varepsilon_{1}$.}

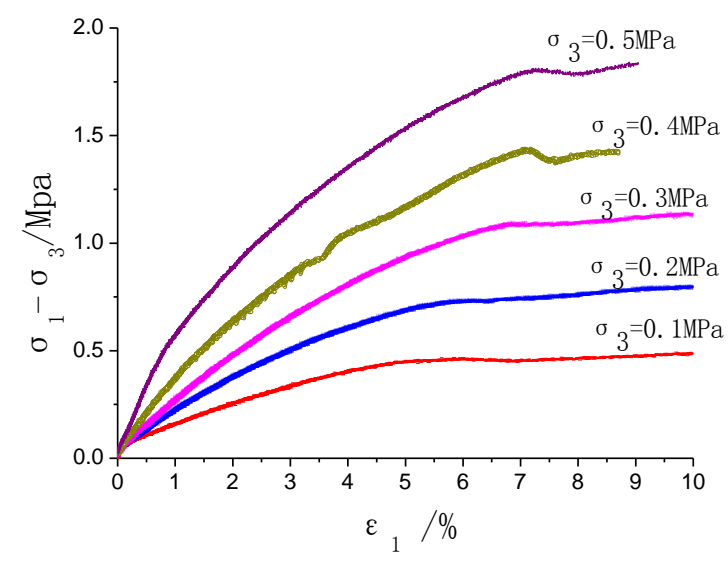

(a) CTC stress path

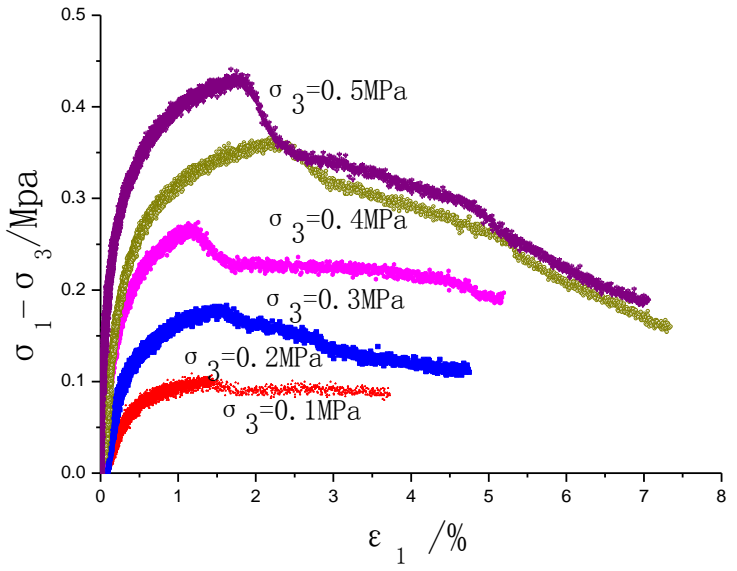

(b) RTC stress path

Figure 3. Relation between $q$ and $\varepsilon_{1}$

Compared Figure 3(a) and 3(b), we can draw some important conclusions are as follows:

(1) The shear strength of the soil under high consolidation pressure was higher than that under low consolidation pressure. Shows the shear strength of the soil depend on its stress history;

(2) Under the same stress history, the $\left(\sigma_{1}-\sigma_{3}\right)_{\max }$ under CTC path is higher than RTC path., as well as the axial strain $\varepsilon_{1}$ while soil reach damage limit state. That show the soil shear strength dependence on its stress path.

(3) Soil show significant hardening under CTC path. On the contrary, it show significant softening under RTC path. This phenomenon is due to the gradual removal of confining pressure while the axial force remains unchanged, the 
sample showed the trend to the collapse of the lateral expansion final.

(4) Figure 3(b) show that, the axial strain growth slowly in the early stages of unloading confining pressure. But axial strain increase quickly when the confining pressure decreases to a certain value. This is consistent with conclusions of the study by Zhang and Chen [16]. It's shown that there is a threshold relationship between confining pressure and axial strain under the RTC path.

\section{2) The relationship between volumetric strain $\varepsilon_{v}$ and axial strain $\varepsilon_{1}$}

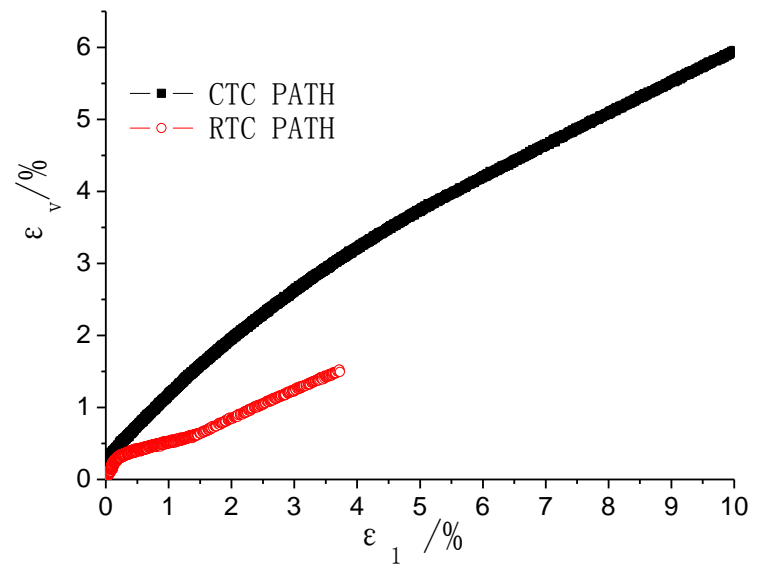

(a) Initial confining pressure $0.1 \mathrm{MPa}$

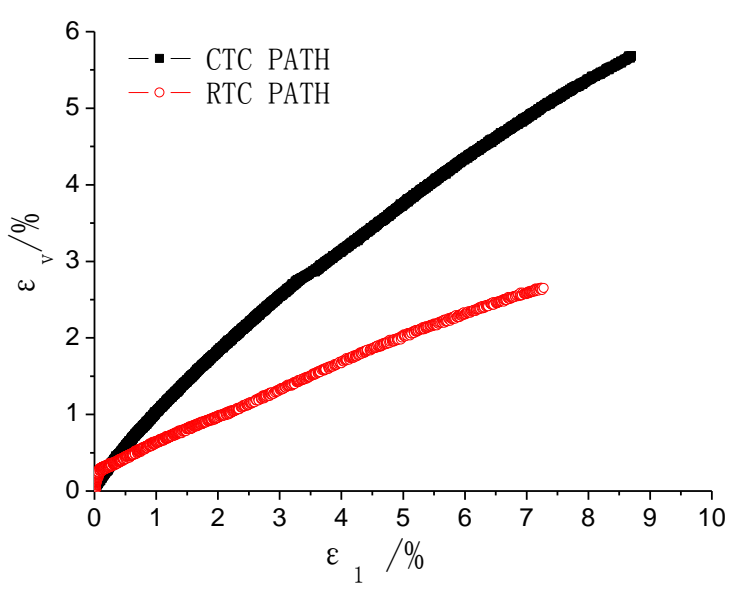

(b) Initial confining pressure 0.4MPa

Figure 4. $\varepsilon_{v}: \varepsilon_{1}$ Relation between CTC path and RTC path

By the different initial confining pressure of the contrast curve, we can draw the following important conclusions:

(1) Axial strain curve indicates that with the increase of volumetric shrinkage character always was cut, and with the increase of the initial consolidation stress the more obvious dilatancy.

(2) Comparing the two test paths, with the growth of axial strain, volumetric growth rate under CTC path is significantly higher than the RTC path. Curve shows that the plane strain tests, whether in the load path, or confining pressure path, the specimen is always showing a reduction of shear character. Viewing from drainage during the test, the volume expansion under loading path is significantly higher than unloading path obviously.

(3) We can be seen from the curves, loading paths has shown non-linear curve, while the unloading curve of the path shown linear curve in the latter part of the approximate straight line.

\section{3) The relation between principal stress ratio and axial strain}

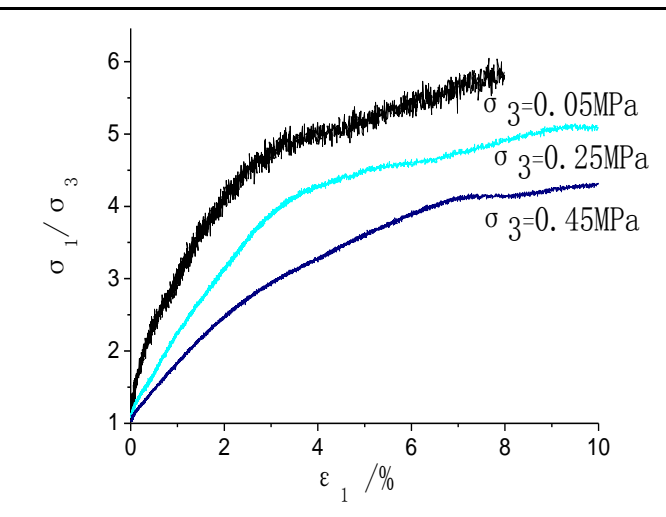

(a) CTC path

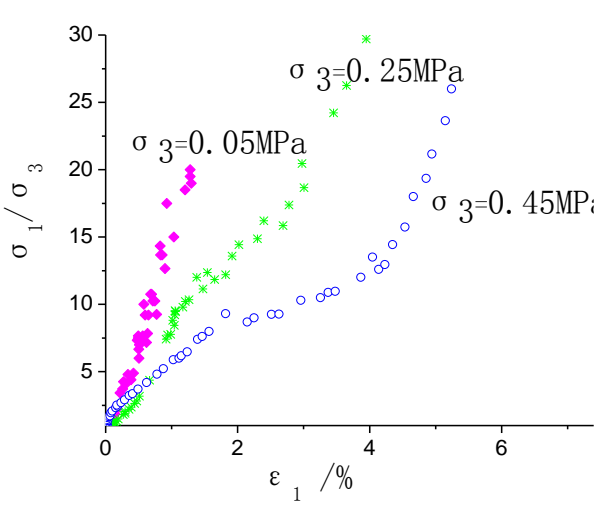

(b) RTC path

Figure 5. Relation between principal stress ratio $\frac{\sigma_{1}}{\sigma_{3}}$ and axial strain $\varepsilon_{1}$

By $\sigma_{1} / \sigma_{3}: \varepsilon_{1}$ relation comparison under loading and unloading path at different initial confining pressure, the 
following conclusions can be obtained:

(1) The curve shape is completely different under loading and unloading path. Axial strain grows quickly under loading path. On the contrary, the axial strain growth slowed down under the unloading path. It is shown again that the influence of stress path on deformation cannot be ignored.

(2) From Figure 5, some conclusions can be drawn that principal stress ratio as the same with two test path, The axial strain of Low initial confining pressure is significantly higher than the high initial confining pressure. That is to say deformation depends on the stress history.

\section{Determination of Modified Cam-Clay Model}

Cam-clay model is developed on the basis of observation of the upper strata of the saturation of soil, remodeling, isotropic consolidation and other properties. Because clay has a different mineral composition, structure, particle size, distribution and stress history, so the conventional model does not accurately simulate the characteristics of soil. But the Cam-clay model can simulate most of the consolidation of normally consolidated soil or mild consolidation soil.

\subsection{Determination of Cam-Clay Model Parameter}

\section{1) Determination of $M$ value}

Determination of break point in accordance with maximum principal stress difference $\left(\sigma_{1}-\sigma_{3}\right)_{\max }$. Destruction of the RTC, the average principal stress path and its corresponding generalized shear stress plotted out in the plane. Plotting the $\mathrm{p}$ and $\mathrm{q}$ in $\mathrm{p}-\mathrm{q}$ plane, The slope of the critical state line $M$ can be obtained by linear fit through the origin, so $M$ is 1.71 , Correlation coefficient $R^{2}=0.991$,Seen from Figure 6 the following.

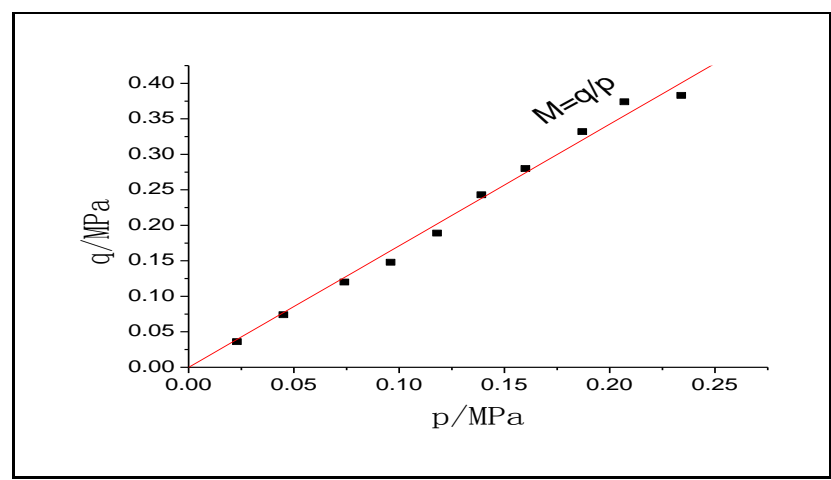

Figure 6. Linear fit of slope of the critical state line under RTC path

\section{2) Determination of $\lambda$ and $\kappa$}

The determination of $\lambda$ and $\kappa$ is obtained by compression rebound test. To ensure the model parameters consistent with the stress path, compression rebound test is under the RTC stress path. Linear fitting for consolidation curve compression in $v-\ln p$ plane, the slope of consolidation line can be obtained. Linear fitting for rebound curve in $v-$ $\ln p$ plane, the slope of rebound $\kappa$ can be obtained. The compression rebound test $v-\ln p$ curve shown in Figure7.

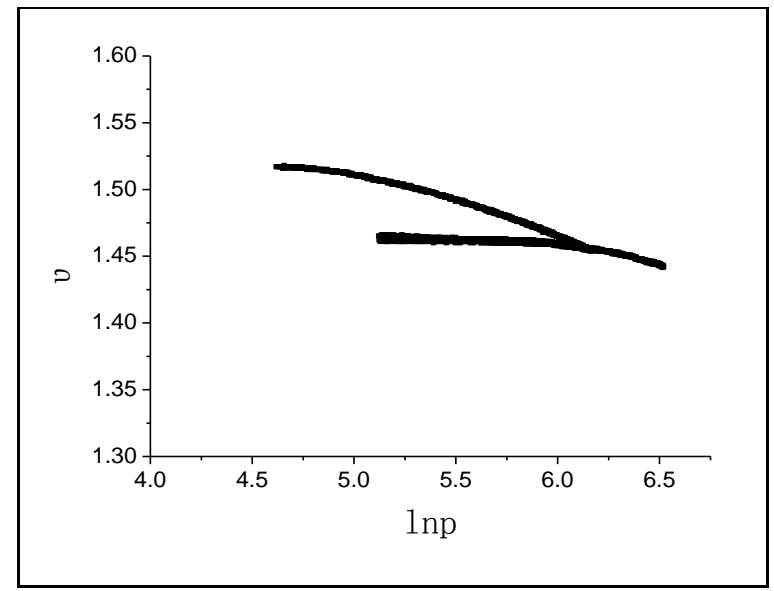

Figure 7. Compression rebound curve

According to Figure 7, the equation of the normal consolidation line as follow: 
$v=N-\lambda \ln p=1.68-0.04 \ln p$

Rebound straight equation as follow:

$v=v_{\kappa}-\kappa \ln p=1.48-0.007 \ln p$

With specific volume $v=1+e, e$ defined as void ratio, $\lambda$ defined as the slope of consolidation compression curve, $\kappa$ defined as the slope of rebound curve. $N$ defined as the $v$ value in Consolidation compression curve when $p=1 K P a$ ,$v_{\kappa}$ defined as the $v$ value in rebound curve when $p=1 \mathrm{KPa}$.

\section{3) Determination of elastic shear modulus}

By the loading and unloading cycle with a drainage tri-axial compression tests, the shear modulus of elasticity of the soil can be measured [17]:

$$
G=327.11 p_{a}\left(\frac{p-q / 3}{p_{a}}\right)^{0.885}
$$

\section{4) Determination of Bulk modulus}

By hydrostatic compression and rebound test, fitting the rebound curve slope base on the $\varepsilon_{v}: p$ relation curve. Then the expression of bulk modulus $\mathrm{K}$ value can derive as following:

$$
G=254.69 p_{a}\left(\frac{p}{p_{a}}\right)^{0.65}
$$

\subsection{Determination of Modified Cam-Clay Model Equation}

The traditional modified Cam-clay model equation as following [18]:

$$
\left(1+\frac{q^{2}}{M^{2} p^{2}}\right) p=p_{a} e^{\left(\frac{1+e_{a}}{\lambda-\kappa} \varepsilon_{v}^{p}\right)}
$$

In which $\mu_{a}$ defined as initial consolidation pressure, and $e_{a}$ defined as initial void ratio. Plastic volume strain $\varepsilon_{v}^{p}$ can be calculated by the following formula:

$$
\varepsilon_{v}^{p}=\varepsilon_{v}-\varepsilon_{v} / K
$$

Taking into account the stress-strain relation characteristics of unloading path, introducing an unloading factor $n$ based on the traditional modified Cam-clay model. Therefore, Equation 5 can be modified as following:

$$
\left(1+\frac{q^{2 n}}{M^{2} p^{2}}\right) p=p_{a} e^{\left(\frac{1+e_{a}}{\lambda-\kappa} \varepsilon_{v}^{p}\right)}
$$

In which unloading factor $n$ can be obtained from tri-axial test with RTC stress path, here $n=1.4$. The final modified Cam-clay model equation of this material as following:

$$
\left(1+\frac{q^{2.8}}{M^{2} p^{2}}\right) p=p_{a} e^{\left(\frac{1+e_{a}}{\lambda-\kappa} \varepsilon_{v}^{p}\right)}
$$

\subsection{Validation of Elastoplastic Constitutive Model}

To test the rationality of this silty clay elasto-plastic constitutive model obtained, Here the mainly for RTC path, experimental values are compared with model predictions. As space is Limited, Listed here only the initial confining pressure was $0.05 \mathrm{MPa}$, and $0.4 \mathrm{MPa}$, compared with $q \sim \varepsilon_{v}^{p}$ relation curve. Analysing the difference between experimental values and model predictions are show in Figure 8. 


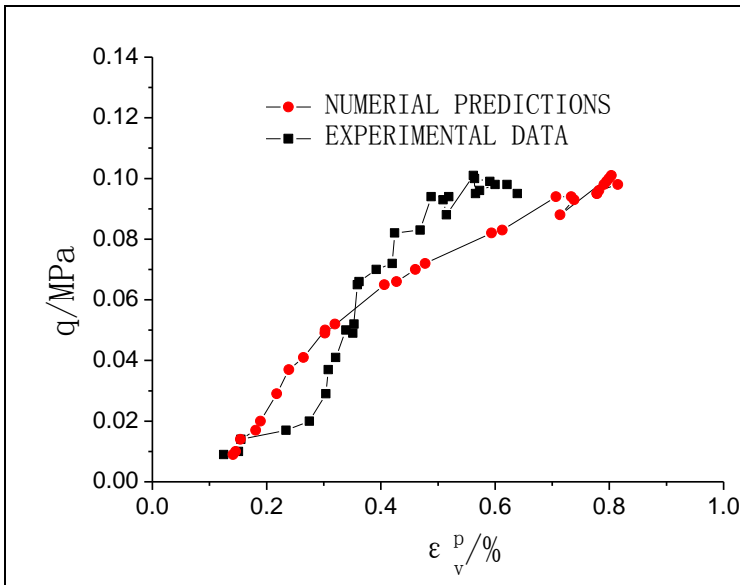

(a) Initial confining pressure $0.1 \mathrm{Mpa}$

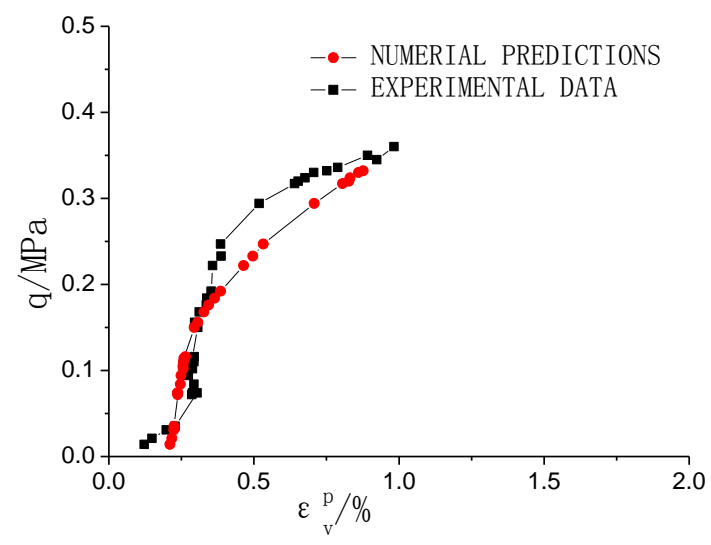

(b) Initial confining pressure $0.4 \mathrm{Mpa}$

Figure 8. $q \sim \varepsilon_{v}^{p}$ relation between experimental data and model predictions

Comparing experimental data with the model predictions in Figure 8, the maximum inaccuracy is within $20 \%$ by calculating with the same shearing stress. Thus the modified Cam-clay model proposed in this work has better applicability

\section{Conclusion}

- Based on the plane strain test data, we have comparatively analysed the mechanical properties difference between CTC path and the RTC path, obtained the correlation between stress-strain behavior of soil and the stress path.

- With the same stress history, the soil under RTC path can reach the critical state line earlier than CTC path. It show that the shear strength under CTC is higher than RTC path. Therefore we can obtain a conclusion that the Stressstrain of the silty clay exist a Strong dependence on stress path.

- With the two stress path, the peak shear strength and deformation of the soil samples with high initial consolidation pressure is higher than a low initial consolidation pressure. It's shown that the stress history effect on soil shear strength and deformation cannot be ignored.

- Through a series of test data, the parameters of cam-clay model has been determine, and the modified Cam-Clay model equations is obtained finally, providing the prerequisite for the numerical prediction.

- As the complexity of geotechnical material, it's difficult to obtain an exact solutions by conventional calculating method. The next work is to compare the measured value of engineering with the model predictions and verifying the effectiveness of the model furthermore, embedding the constitutive model obtained from test into the numerical analysis program, drawing support its strong non-linear numerical analysis simulation capability, conducting numerical analysis link to a deep excavation.

\section{Funding}

The work was supported by the national natural science foundation of china [grant number 51478201]; the Innovation foundation in youth science and technology team of hubei province [grant number T201823]; the natural science fund of hubei Province [grant number 2012FKC14201]; the scientific sesearch fund of hubei provincial education department [grant number D20134401]; and the innovation foundation in youth team of hubei polytechnic university [grant number Y0008].

\section{References}

[1] LambeT. W."Stress path method.”.Journal of the Soil Mechanics and Foundations Division, ASCE, 1967,93(SM6):309 - 331.

[2] LambeT. W., MarrW. A. "Stress path method, Second Education." Journal of the Geotechnical Engineering Division. ASCE,1979,105(GT6):727-738.doi:10.1016/0148-9062(79)90036-6.

[3] Qin S. L., Yang L. Q., GAO H., et al. "Experimental Study of Mechanical Properties of Coarse Aggregates of Sericite Schist Under Different Stress Paths.“ Chinese Journal of Rock Mechanics and Engineering. 2014,33(9):1 932-1 938. doi:10.13722/j.cnki.jrme.2014.09.025.

[4] Zhao J. J. ,Jiang X.. “Test Research of Mechanical Properties of Marine Soft Soil under Unloading Stress Path”. Journal of Tianjin CHENGJIAN University. 2015,21(4):267-272. doi:10.3969/j.issn.1006-6853.2015.04.007. 
[5] Li X. B., Guo L., Cai Y. Q., Hu X. Q..” Stress path tri-axial tests on K0-consolidated saturated soft clay”. Journal of Central South University (Science and Technology). 2015, 46(5):1820-1825. doi:10.11817/j.issn.1672-7207.2015.05.033.

[6] Charles W. W. Ng. "Stress paths in relation to deep excavation". Journal of Geotechnical and Geoenvironmental Engineering, 1999,125(5):357-363.doi:10.1061/(asce)1090-0241(1999)125:5(357).

[7] Yuan J., Gong X. N.. "Analysis of soft clay during excavation". Journal of Zhejiang University (Engineering Science),2001,35(5):465-470.doi:10.3785/j.issn.1008-973X.2001.05.001.

[8] Cheng T., Yan K. Q. "Numerical simulation for influences of stress paths on earth's surface deformation". Rock and Soil Mechanics, 2010 , 31 (2):661-666. Doi:10.3969/j.issn.1000-7598.2010.02.055

[9] Chen K., Yan S. W., Sun L. Q., et al. “ Analysis of deformation of deep foundation pit under excavation unloading condition”. Rock and Soil Mechanics. 2016,37(4).doi:10.16285/j.rsm.2016.04.021.

[10] Zhang K. Y., ,Li G. S., Mei X. H., et al. "Stress-deformation characteristics of silty soil based on K0 consolidation and drainage unloading stress path tests” Chinese Journal of Geotechnical Engineering. 2017 39(7).doi:10.11779/CJGE201707003.

[11] Cheng, T., Wang, J. T., Yan, K. Q., et al. "Coupling analysis method for elastoplastic consolidation of clay considering stress paths". Chinese Journal of Rock Mechanics and Engineering, 2008, 27(5): 403-412. doi:10.3321/j.issn:1000-6915.2008.02.025

[12] Cheng T., Yan K. Q., Zheng J. J., et al. "Semi-analytical and semi-numerical method for plane strain consolidation of doublelayer foundation considering stress paths". European Journal of Environmental and Civil Engineering, 2017,21(10):1187-1216. doi $10.1080 / 19648189.2016 .1150903$

[13] Cheng T., Yan K. Q., Zheng J. J., et al. "Semi-analytical and semi-numerical method for the single soil layer consolidation problem” Engineering Computations, 2017,34(3):960-987. doi: 10.1108/EC-10-2015-0297

[14] Feng T. G., Jiang Z. Q. "Research of constitutive models reflecting stress-strain relationship in lateral unloading conditions." Journal of PLA University of Science and Technology (Natural Science Edition). 2013, 14(2):202-206.doi: 10.3969/j.issn.10093443.2012.09.040.

[15] Cheng, T., "Study on numerical modeling and consolidation problem of clay", PhD Diss.,Huazhong University of Science and Technology, 2006

[16] Zhang R.T., Chen S. Y. "An experimental study on stress-strain behavior of soft clay along decreasing average normal stress”.Rock and Soil Mechanics, 2002,23(5):612-616.doi:10.3969/j.issn.1000-7598.2002.05.019.

[17] Lu P. Y., Chen S. Y., Xiong L. Z., et al. "Elastoplastic Constitutive Equation for Hydraulic-fill Soil of Slurry-fall Dam”. Chinese Journal of Geotechnical Engineering, 1984,6(2):23-39.

[18] Cheng T., Yan K. Q., Zhang H. Z., et al. " Uniform nonlinear constitutive model and parameters for clay in different consolidation conditions based on regressing method”. 2014, (5):1-8. doi: 10.1155/2014/804586.

[19] Zhang, Y., Kim, C.W., Beer, M., Dai, H., Guedes Soares, C., "Modeling multivariate ocean data using asymmetric copulas." Coastal Engineering, 2018, 135, 91-111. DOI: 10.1016/j.coastaleng.2018.01.008.

[20] Zhang, Y., Kim, C.W., Tee, K.F. "Maintenance management of offshore structures using Markov process model with random transition probabilities." Structure and Infrastructure Engineering, 2017, 13(8), 1068-1080. DOI: 10.1080/15732479.2016.1236393.

[21] Zhang, Y., Lam, J.S.L. "Estimating economic losses of industry clusters due to port disruptions.” Transportation Research Part A: Policy and Practice, 2016, 91, 17-33. DOI: 10.1016/j.tra.2016.05.017.

[22] Zhang, Y. “A fuzzy residual strength based fatigue life prediction method.” Structural Engineering and Mechanics, 2015, 56(2), 201-221. DOI: 10.12989/sem.2015.56.2.201.

[23] Zhang, Y., Lam, J.S.L. "Reliability analysis of offshore structures within a time varying environment." Stochastic Environmental Research and Risk Assessment, 2015, 29(6), 1615-1636. DOI: 10.1007/s00477-015-1084-7. 